\title{
Expression of BMP-4 and Smad1 in patients with Hirschsprung disease and its clinical significance
}

\author{
JIANJUN ZHANG ${ }^{1}$ and FENGLI LIU ${ }^{2}$ \\ Departments of ${ }^{1}$ Gastroenterology and ${ }^{2}$ Neonatal Surgery, Xuzhou Children's Hospital, \\ Xuzhou Medical University, Xuzhou, Jiangsu 221000, P.R. China
}

Received November 13, 2018; Accepted March 4, 2019

DOI: $10.3892 /$ etm.2019.7530

\begin{abstract}
Expression and clinical significance of bone morphogenetic protein (BMP)-4 and Smad1 in patients with Hirschsprung disease (HD) were investigated. A retrospective analysis of $96 \mathrm{HD}$ patients (experimental group) admitted to Xuzhou Children's Hospital, Xuzhou Medical University from June 2015 to June 2017 was performed.According to the samples, the experimental group was divided into the stenosis group, the transition group and the expansion group. Forty-seven children with colostomy due to intestinal obstruction were selected as the control group. The expression levels of BMP-4 and Smad1 proteins were detected by immunohistochemical staining. The expression levels of BMP-4 and Smad mRNA were detected by real-time quantitative PCR (RT-qPCR), and were quantified and compared. Via immunohistochemistry, BMP-4 and Smad1 proteins were detected in the samples of different parts of HD patients and children with intestinal obstruction. The positive expression levels of BMP-4 and Smad1 proteins in the transition group were decreased compared with those in the expansion and control groups $(\mathrm{P}<0.05)$, and the positive expression levels of BMP-4 and Smad1 proteins in the stenosis group were decreased compared with those in the transition, expansion, and control groups $(\mathrm{P}<0.05)$. Also, the gene expression levels of BMP-4 and Smad1 in the transition and stenosis groups were successively decreased, and the differences were statistically significant $(\mathrm{P}<0.05)$. In conclusion, the expression of BMP-4 and Smad1 in the intestinal plexus of HD lesions was significantly reduced, indicating that BMP-4 and Smad1 are closely related to the occurrence of $\mathrm{HD}$, and it is suspected that they have a certain influence on the intestinal development of congenital digestive tract malformations.
\end{abstract}

Correspondence to: Dr Fengli Liu, Department of Neonatal Surgery, Xuzhou Children's Hospital, Xuzhou Medical University, 18 Sudi Bei Road, Xuzhou, Jiangsu 221000, P.R. China E-mail: liufengli361@163.com; xzsetyywklf1@163.com

Key words: bone morphogenetic protein-4, Smad1, Hirschsprung disease, mRNA expression, clinical significance

\section{Introduction}

Hirschsprung's disease (HD), also known as aganglionosis, is a common pediatric surgical digestive tract malformation disease (1). Some studies (2) have suggested that the lesional intestine of HD may be caused by the abnormality of nerve ridge cells in the process of migration and differentiation into the intestinal wall, resulting in the loss of ganglion cells in the sphincter and submucosal plexus. Other studies (3) have reported that as long as any process of biological function, such as proliferation and differentiation of intestinal nerve ridge cells, is impeded it can lead to the occurrence of HD. In recent years, the cause of HD has been more related to the congenital malformation of multiple genes, and has certain family hereditary origin $(4,5)$. However, there is currently no detailed study on the pathogenesis of HD.

In recent years, with the continuous development of molecular biology, a variety of genes have been found to be associated with HD pathogenesis (6). Although some studies (7) have reported that the abnormalities of these genes may be responsible for the pathogenesis of HD, subsequent studies have found that the mutations of these genes have certain limitations, and the etiology of all HD cases cannot be explained. However, as proteins and genes, diagnosis and treatment of diseases are deeply studied investigating etiology, a secreted polypeptide signaling molecule and transforming growth factor- $\beta$ (TGF- $\beta$ ) super family has been discovered. This is a class of cytokines with versatility and extensive biological activity, which have an impact on biological processes, such as cell growth, proliferation and apoptosis (8). Bone morphogenetic proteins (BMPs) are members of the TGF- $\beta$ superfamily (9). Their mechanism of action is that R-Smads are used as signal transducers by BMPs. BMP-4 forms a complex with phosphorylated Smad1. Then, it enters the nucleus from the cytoplasm and binds to DNA, which regulates the transcription of BMP target genes (10). Smad is a very important step in the TGF- $\beta$ signaling pathway, as it regulates the progression of TGF- $\beta$ signaling from the cell membrane into the nucleus (11). As a member of the BMP family, BMP-4 has been found to be related to the development and maturation of the enteric nervous system (12), while Smad1 has been found to be expressed in the mitosis of spinal cord neurons and play an important role in the development of the nervous system (13). 
Currently, there are no studies on the specific roles and mechanisms of BMP-4 and Smad1 in HD etiology. Therefore, in the present study, the expression and clinical significance of BMP-4 and Smad1 protein and mRNA in HD patients were investigated in order to provide new methods for the treatment of clinical HD and a new theoretical basis for the its pathogenesis.

\section{Subjects and methods}

General information. A retrospective analysis of $96 \mathrm{HD}$ patients (experimental group) admitted to Xuzhou Children's Hospital, Xuzhou Medical University (Xuzhou, China) from June 2015 to June 2017 was performed. The average age of all children was $2.03 \pm 1.28$ years, including 37 males and 59 females. Among them, 38 cases were typical short-segment HD patients with rectal or sigmoid colon, 35 cases were of long-segment type, and 23 cases of whole colon type. According to the samples taken, the experimental group was divided into the stenosis group, the transition group and the expansion group. Forty-seven children with colostomy due to intestinal obstruction were selected as the control group. There was no significant difference in sex, age, BMI and height between the experimental and control group $(\mathrm{P}>0.05)$ (Table I). Inclusion criteria: children having undergone rectal mucosal biopsy and $\mathrm{X}$-ray barium enema (diagnosed as HD). Exclusion criteria: children with other serious organ diseases or other gastrointestinal disorders. All the families of the children agreed to participate in the experiment and signed an informed consent form. The study was approved by the Ethics Committee of Xuzhou Children's Hospital, Xuzhou Medical University.

Experimental materials and reagents. BMP-4 immunohistochemistry kit and Smad1 immunohistochemistry kit were purchased from Cell Signaling Technology, Inc. (Danvers, MA, USA). The microscope used was purchased from Olympus Corp. (Tokyo, Japan). DAB kit was purchased from MXB Biotechnologies (Fuzhou, China), TRIzol reagent was purchased from Applied Biosystems (Applied Biosystems; Thermo Fisher Scientific, Inc., Waltham, MA, USA), SYBR-Green RT-qPCR kit and 2X PCR Master Mix reverse transcription kit were purchased from Takara Biotechnology Co., Ltd. (Dalian, China), quantitative PCR instrument was purchased from Bio-Rad Laboratories, Inc. (Hercules, CA, USA), and all primers were synthesized by Shanghai Jima Biotech Co., Ltd. (Shanghai, China).

Immunohistochemistry detection of BMP-4 and Smadl expression in different groups of children. Firstly, each group of samples, obtained after operation, was made into paraffin sections with a thickness of $\sim 3 \mu \mathrm{m}$ for further use, and then detected by immunohistochemistry. The details of the specific detection method are as follows: every sample was fixed in $4 \%$ paraformaldehyde buffer at $4^{\circ} \mathrm{C}$ for $24 \mathrm{~h}$. Paraffin samples were routinely dewaxed and then rinsed 3 times with PBS for $5 \mathrm{~min}$ each. After rinsing, the antigen retrieval solution was incubated at room temperature for $10 \mathrm{~min}$ and washed 3 times with PBS. Then, $10 \%$ milk protein was added to each section for sealing and incubation was continued for $10 \mathrm{~min}$ at room temperature. A total of $50 \mu 1$ of primary antibodies
Table I. General information.

\begin{tabular}{lcccc}
\hline & $\begin{array}{c}\text { Experimental } \\
\text { group } \\
\text { Factors }\end{array}$ & $\begin{array}{c}\text { Control } \\
\text { group } \\
(\mathrm{n}=96)\end{array}$ & $\chi^{2}$ value & P-value \\
\hline Sex & & & 0.076 & 0.784 \\
$\quad$ Male & $37(38.54)$ & $17(36.17)$ & & \\
$\quad$ Female & $59(61.46)$ & $30(63.83)$ & & \\
Age (years) & & & 0.068 & 0.795 \\
$\geq 2$ & $41(42.71)$ & $19(40.43)$ & & \\
$<2$ & $55(57.29)$ & $28(59.57)$ & & \\
BMI (kg/m $)$ & & & 0.061 & 0.805 \\
$\geq 10$ & $45(46.88)$ & $21(44.68)$ & & \\
$<10$ & $51(53.13)$ & $26(55.32)$ & & \\
Height (cm) & & & 0.064 & 0.800 \\
$\geq 70$ & $43(44.79)$ & $20(42.55)$ & & \\
$<70$ & $53(55.21)$ & $27(57.45)$ & & \\
Type & & & - & - \\
Short segment & $38(39.58)$ & - & & \\
Long segment & $35(36.46)$ & - & & \\
Full colon & $23(23.96)$ & - & & \\
Family genetic history & & & - & - \\
Existent & $72(75.00)$ & - & & \\
Non-existent & $24(25.00)$ & - & & \\
\hline
\end{tabular}

(rabbit anti-human BMP-4 and Smad1 monoclonal antibodies; dilution, 1:1,000; cat. nos. ab124715 and ab63356; Abcam, Cambridge, MA, USA) were added and the samples were left overnight at $4^{\circ} \mathrm{C}$. Then, PBS was used for rinsing, and the secondary antibody (biotinylated goat anti-rabbit IgG; dilution, 1:500; cat. no. ab6720; Abcam) was added after removing the PBS solution. Next, it was incubated at room temperature for 30 min and rinsed with PBS. After being incubated at room temperature for $10 \mathrm{~min}$, freshly prepared DAB (20:1:1) was applied for coloring. Every sample was washed with BPS to terminate coloring, and finally the samples were colored with hematoxylin for $1 \mathrm{~min}$. Next, water was dehydrated with 80 , 90 and $100 \%$ alcohol. After the neutral gum was sealed, it was clustered and photographed with a microscope. The samples of the primary antibody were replaced with PBS as a negative control, and the following procedures were the same as above. The expression levels of BMP-4 and Smad1 protein in different groups of children were compared when brown-to-brown particles in the cytoplasm were identified.

RT-qPCR detection of BMP-4 and Smad1 mRNA expression in different groups of children. The obtained tissues were first treated and then total RNA of BMP-4 and Smad1 was extracted by adding TRIzol reagent. The purity and concentration of RNA were detected by ultraviolet spectrophotometer (Shanghai Metash Instruments Co., Ltd., Shanghai, China) and $1 \mu \mathrm{g}$ of total RNA was obtained. cDNA was synthesized by reverse transcription according to the 2X PCR Master Mix, and the reaction conditions were as follows: $37^{\circ} \mathrm{C}$ for $15 \mathrm{~min}, 85^{\circ} \mathrm{C}$ for $5 \mathrm{sec}$. After reverse transcription, $2 \mu 1$ of the synthesized 
Table II. Primer sequences.

\begin{tabular}{lll}
\hline Genes & \multicolumn{1}{c}{ Upstream primers } & \multicolumn{1}{c}{ Downstream primers } \\
\hline BMP-4 & 5'-TCCTGGTAACCGAATGCT-3' & 5'-CACCTGCTCCCGAAATAG-3' \\
Smad1 & 5'-CAGCAGAGGAGATGTTCAGGCA-3' & 5'-TGCACGAAGATGCTGCTGTCAC-3' \\
$\beta$-actin & 5'-AGATGTGGACAGCAAGCAG-3' & 5'-GCGCAAGTTAGGTTTTGTCA-3'
\end{tabular}

BMP-4, bone morphogenetic protein-4.

Table III. Comparison of BMP-4 and Smad1 positive protein expression levels among four groups.

\begin{tabular}{lccccr}
\hline Factors & $\begin{array}{c}\text { Stenosis group } \\
(\mathrm{n}=31)\end{array}$ & $\begin{array}{c}\text { Transition group } \\
(\mathrm{n}=33)\end{array}$ & $\begin{array}{c}\text { Expansion group } \\
(\mathrm{n}=32)\end{array}$ & $\begin{array}{c}\text { Control group } \\
(\mathrm{n}=47)\end{array}$ & $\begin{array}{c}\text { F value } \\
\text { P-value }\end{array}$ \\
\hline BMP-4 & $133.54 \pm 2.76^{\mathrm{a}-\mathrm{c}}$ & $165.03 \pm 2.42^{\mathrm{a}, \mathrm{b}}$ & $201.67 \pm 2.16$ & $208.32 \pm 3.19$ & 6,080 \\
Smad1 & $112.46 \pm 2.02^{\mathrm{a}-\mathrm{c}}$ & $144.29 \pm 2.17^{\mathrm{a}, \mathrm{b}}$ & $205.33 \pm 2.63$ & $212.41 \pm 3.58$ & 10,636 \\
\hline
\end{tabular}

${ }^{a} \mathrm{P}<0.05$, compared with the control group; ${ }^{b} \mathrm{P}<0.05$, compared with the expansion group; ${ }^{\mathrm{c}} \mathrm{P}<0.05$, compared with the transition group. BMP-4, bone morphogenetic protein-4.

cDNA were taken for $\mathrm{qPCR}$. The reaction conditions were: pre-denaturation at $95^{\circ} \mathrm{C}$ for $30 \mathrm{sec}, 95^{\circ} \mathrm{C}$ for $5 \mathrm{sec}, 65^{\circ} \mathrm{C}$ for $30 \mathrm{sec}$, and finally $65^{\circ} \mathrm{C}$ for $15 \mathrm{sec}$. Reaction conditions: pre-denaturation at $95^{\circ} \mathrm{C}$ for $30 \mathrm{sec}, 95^{\circ} \mathrm{C}$ for $5 \mathrm{sec}, 65^{\circ} \mathrm{C}$ for $30 \mathrm{sec}$, finally $65^{\circ} \mathrm{C}$ for $15 \mathrm{sec}$ and $95^{\circ} \mathrm{C}$ for $5 \mathrm{sec}$ as extension, repeated 40 times. $\beta$-actin was used as an internal reference substance. Primer sequences are shown in Table II. The relative expression of the gene was quantified using the $2^{-\Delta \mathrm{Cq}}$ method (14), and fluorescent qPCR was performed by a qPCR instrument. The experiment was repeated 3 times.

Statistical analysis. In this study, SPSS 18.0 software package (Bizinsight, Beijing, China) was used for the statistical analysis of the experimental data. Measurement data were expressed as the mean \pm standard deviation. t-test was used for the comparison between two groups, one-way analysis of variance was used for the comparison between multiple groups and LSD was the post hoc test. Chi-square test was used for count data. The experimental graphs were produced using GraphPad Prism 6 software (GraphPad Software, Inc., La Jolla, CA, USA). P $<0.05$ was considered to indicate a statistically significant difference.

\section{Results}

Immunohistochemical detection of the positive expression levels of BMP-4 and Smadl proteins in the four groups of children. According to the location of the specimens taken, the subjects were divided into stenosis group $(n=31)$, transition group $(n=33)$, and expansion group $(n=32)$. There was no significant difference in the expression of BMP-4 and Smad1 proteins between the control and the expansion group $(\mathrm{P}>0.05)$. The positive expression levels of BMP-4 and Smad1 proteins in the transition group were decreased compared with those in the expansion and control groups

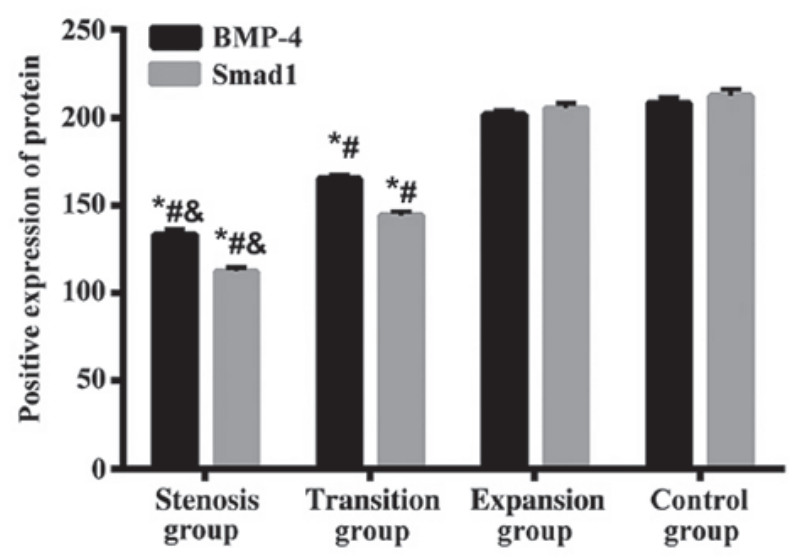

Figure 1. Immunohistochemistry was used to detect the positive expression of BMP-4 and Smad1 proteins in the four groups of samples. There was no significant difference in the expression of BMP-4 and Smad1 proteins between the control and the expansion group $(\mathrm{P}>0.05)$. The positive expression levels of BMP-4 and Smad1 proteins in the transition group were decreased compared with those in the expansion and control groups, and the positive expression levels of BMP-4 and Smad1 proteins in the stenosis group were decreased compared with those in the transition, expansion, and control groups. ${ }^{*} \mathrm{P}<0.05$, compared with the control group; ${ }^{\text {}} \mathrm{P}<0.05$, compared with the expansion group; ${ }^{\circledR} \mathrm{P}<0.05$, compared with the transition group. BMP-4, bone morphogenetic protein- 4 .

$(\mathrm{P}<0.05)$, and the positive expression levels of BMP-4 and Smad1 proteins in the stenosis group were decreased compared with those in the transition, expansion, and control groups $(\mathrm{P}<0.05)$ (Table III, Fig. 1).

$R T-q P C R$ mRNA detection results. The expression of BMP-4 gene in the stenotic and transitional segments of HD was significantly lower than that in the control group and the expansion group and the differences were statistically significant $(\mathrm{P}<0.05)$. The data in expansion group were slightly lower 
Table IV. Comparison of BMP-4 and Smad1 mRNA expression levels among four groups.

\begin{tabular}{lcccccr}
\hline Factors & $\begin{array}{c}\text { Stenosis group } \\
(\mathrm{n}=31)\end{array}$ & $\begin{array}{c}\text { Transition group } \\
(\mathrm{n}=33)\end{array}$ & $\begin{array}{c}\text { Expansion group } \\
(\mathrm{n}=32)\end{array}$ & $\begin{array}{c}\text { Control group } \\
(\mathrm{n}=47)\end{array}$ & F value & P-value \\
\hline BMP-4 & $0.32 \pm 0.08^{\mathrm{a}-\mathrm{c}}$ & $0.46 \pm 0.07^{\mathrm{a}, \mathrm{b}}$ & $1.17 \pm 0.11$ & $1.21 \pm 0.13$ & 711.8 & $<0.001$ \\
Smad1 & $0.27 \pm 0.04^{\mathrm{a}-\mathrm{c}}$ & $0.59 \pm 0.12^{\mathrm{a}, \mathrm{b}}$ & $0.97 \pm 0.04$ & $1.06 \pm 0.09$ & 739.7 & $<0.001$ \\
\hline
\end{tabular}

${ }^{\mathrm{a}} \mathrm{P}<0.05$, compared with the control group; ${ }^{\mathrm{b}} \mathrm{P}<0.05$, compared with the expansion group; ${ }^{\mathrm{c}} \mathrm{P}<0.05$, compared with transition group. $\mathrm{BMP}-4$, bone morphogenetic protein- 4 .

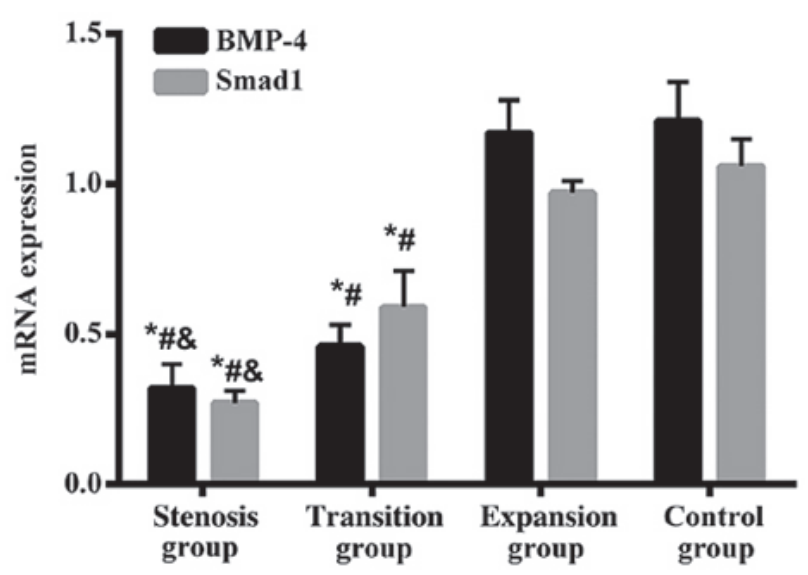

Figure 2. RT-qPCR was used to detect the expression of BMP-4 and Smad1 mRNA in the four groups of samples. There was no significant difference in the expression of BMP-4 and Smad1 mRNA between the control and the expansion group ( $\mathrm{P}>0.05)$. However, the expression levels of BMP-4 and Smad1 mRNA in the transition and stenosis groups decreased successively, and the differences were statistically significant. ${ }^{*} \mathrm{P}<0.05$, compared with the control group; ${ }^{\text {P}} \mathrm{P}<0.05$, compared with the expansion group; ${ }^{\circledR} \mathrm{P}<0.05$ compared with the transition group. BMP-4, bone morphogenetic protein- 4 .

than that in the control group, but there was no significant difference $(\mathrm{P}>0.05)$. The expression level of BMP-4 gene was gradually decreased from the expansion group to the stenosis group, and the differences were statistically significant $(\mathrm{P}<0.05)$. The expression of Smad1 gene in the stenotic and transitional segments of HD was significantly lower than that in the control group and the expansion group, and the differences were statistically significant $(\mathrm{P}<0.05)$. The data in expansion group were slightly lower than that in the control group, but there was no significant difference $(\mathrm{P}>0.05)$. The expression level of Smad1 gene was gradually decreased from the expansion group to the stenosis group, and the differences were statistically significant $(\mathrm{p}<0.05)$ (Table IV and Fig. 2).

\section{Discussion}

The enteric nervous system is part of the direct control of the gastrointestinal tract by the autonomic nervous system. Cells called neural crest can differentiate and derive cell populations. However, once the neural crest cells are missing, this may lead to intestinal ganglion neurons, which is Hirschsprung disease (HD) (15). HD is a digestive tract malformation disease that occurs in children with benign hyperplasia. HD's usual symptoms are constipation and bloating in children, and may lead to nutritional malabsorption and hypoevolutism (16). Currently, many studies have shown that the occurrence of HD has complex genetic factors. The idea is that the pathogenesis is more unified, because when the migration process of neural crest cells is affected, the intestinal wall cannot colonize the neural crest cells derived from the enteric nervous system causing HD to occur (17). In a study of the molecular biology of HD, it was found that the BMP/Smad pathway plays a very important role in the development of the nervous system at various stages and sites (18). As a member of the BMP family, it has been found that BMP-4 is critical for the intestinal development (19). Smad1 is a receptor-activated Smad, an intracellular signaling molecule belonging to BMPs (20). Some studies (21) have found the presence of phosphorylated Smad1 in enteric ganglion cells. Abnormal regulation of the BMP/Smad signaling pathway leads to a variety of development-related diseases (22), and some studies (23) have demonstrated that BMP-4 and Smad1 play key roles in intestinal development. However, the specific expression and effect of BMP-4 and Smad1 proteins and mRNAs in HD patients have rarely been studied, therefore the present study explored the expression and clinical significance of BMP-4 and Smad1 protein and mRNA in HD patients.

Pathogenesis is a complex multi-factorial process. In the present study, we first used immunohistochemistry to detect BMP-4 and Smad1 proteins in samples from different parts of HD patients and children with intestinal obstruction. There was no significant difference in the expression of BMP-4 and Smad1 proteins between the control and the expansion group $(\mathrm{P}>0.05)$. The positive expression levels of BMP-4 and Smad1 proteins in the transition group were decreased compared with those in the expansion and control groups $(\mathrm{P}<0.05)$, and the positive expression levels of BMP-4 and Smad1 proteins in the stenosis group were decreased compared with those in the transition, expansion, and control groups $(\mathrm{P}<0.05)$. Then we used RT-qPCR to detect the expression of BMP-4 and Smad1 mRNA in the samples from different parts of HD patients and children with intestinal obstruction. The results showed that there was no significant difference in the expression of BMP-4 and Smad1 genes between the control and the expansion group ( $\mathrm{P}>0.05$ ), but the expression levels of BMP-4 and Smad1 in the transition and stenosis group decreased successively, and the differences were statistically significant $(\mathrm{P}<0.05)$. The results above suggest that there is an abnormal expression of BMP-4 and Smad1 in children with HD. Some studies (24) have shown that abnormal expression of BMP-4 and Smad1 has an effect on the expression of downstream signaling molecules, therefore the growth and differentiation of ganglion cells are 
effected. So we hypothesized that BMP-4 and Smad1 may interact with each other during the development of ganglion cells, influencing the development and function of the intestinal nervous system. An in vitro study of BMP-4 (25) has found that the overexpression of BMP-4 in mice can cause intestinal development defects in mice, which is also confirmed by our conclusion of BMP-4. However, there is no relevant study on the expression of Smad1 in children with HD.

In summary, the expression levels of BMP-4 and Smad1 in the plexus of HD lesions were significantly reduced, indicating that BMP-4 and Smad1 are closely related to the occurrence of $\mathrm{HD}$, and it is speculated that they have a certain influence on the intestinal development of congenital digestive tract malformations, which provides a theoretical basis for the subsequent research on the pathogenesis of HD.

\section{Acknowledgements}

Not applicable.

\section{Funding}

No funding was received.

\section{Availability of data and materials}

The datasets used and/or analyzed during the present study are available from the corresponding author on reasonable request.

\section{Authors' contributions}

JZ assisted with immunohistochemistry and was responsible for the drafting of the manuscript. JZ and FL performed PCR. Both authors read and approved the final manuscript.

\section{Ethics approval and consent to participate}

The study was approved by the Ethics Committee of Xuzhou Children's Hospital, Xuzhou Medical University (Xuzhou, China). Signed informed consents were obtained from the parents of the child patients.

\section{Patient consent for publication}

Not applicable.

\section{Competing interests}

The authors declare that they have no competing interests.

\section{References}

1. Kenny SE, Tam PK and Garcia-Barcelo M: Hirschsprung's disease. Semin Pediatr Surg 19: 194-200, 2010

2. Tam PK and Garcia-Barceló M: Genetic basis of Hirschsprung's disease. Pediatr Surg Int 25: 543-558, 2009.

3. Heanue TA and Pachnis V: Enteric nervous system development and Hirschsprung's disease: Advances in genetic and stem cell studies. Nat Rev Neurosci 8: 466-479, 2007.

4. Zhang Z, Jiang Q, Li Q, Cheng W, Qiao G, Xiao P, Gan L, Su L, Miao C and Li L: Genotyping analysis of 3 RET polymorphisms demonstrates low somatic mutation rate in Chinese Hirschsprung disease patients. Int J Clin Exp Pathol 8: 5528-5534, 2015.
5. Kapur RP: Practical pathology and genetics of Hirschsprung's disease. Semin Pediatr Surg 18: 212-223, 2009.

6. Anderson SR, Lee I, Ebeling C, Stephenson DA, Schweitzer KM, Baxter D, Moon TM, LaPierre S, Jaques B, Silvius D, et al: Disrupted SOX10 function causes spongiform neurodegeneration in gray tremor mice. Mamm Genome 26: 80-93, 2015.

7. Ferreira R, Nilsson JR, Solano C, Andréasson J and Grøtli M: Design, synthesis and inhibitory activity of photoswitchable RET kinase inhibitors. Sci Rep 5: 9769, 2015.

8. McGehee AM, Moss BJ and Juo P: The DAF-7/TGF- $\beta$ signaling pathway regulates abundance of the Caenorhabditis elegans glutamate receptor GLR-1. Mol Cell Neurosci 67: 66-74, 2015.

9. Dias JM, Alekseenko Z, Applequist JM and Ericson J: TGF $\beta$ signaling regulates temporal neurogenesis and potency of neural stem cells in the CNS. Neuron 84: 927-939, 2014.

10. Wang XB, Wang W, Zhu XC, Ye WJ, Cai H, Wu PL, Huang XY and Wang LX: The potential of asiaticoside for TGF- $\beta 1 /$ Smad signaling inhibition in prevention and progression of hypoxia-induced pulmonary hypertension. Life Sci 137: 56-64, 2015.

11. Hatakeyama Y, Nguyen J, Wang X, Nuckolls GH and Shum L: Smad signaling in mesenchymal and chondroprogenitor cells. J Bone Joint Surg Am 85-A (Suppl 3): 13-18, 2003.

12. Fukuda $\mathrm{S}$ and Taga T: Roles of BMP in the development of the central nervous system. Clin Calcium 16: 781-785, 2006 (In Japanese).

13. Weng Q, Chen Y, Wang H, Xu X, Yang B, He Q, Shou W, Chen Y, Higashi $\mathrm{Y}$, van den Berghe $\mathrm{V}$, et al: Dual-mode modulation of Smad signaling by Smad-interacting protein Sip1 is required for myelination in the central nervous system. Neuron 73: 713-728, 2012.

14. Mohelnikova-Duchonova B, Oliverius M, Honsova E and Soucek P: Evaluation of reference genes and normalization strategy for quantitative real-time PCR in human pancreatic carcinoma. Dis Markers 32: 203-210, 2012.

15. Pontarelli EM, Ford HR and Gayer CP: Recent developments in Hirschsprung's-associated enterocolitis. Curr Gastroenterol Rep 15: 340, 2013.

16. Mohammed AA and Gahukamble DB: Concordant expression of Hirschsprung's disease in monozygous twins. Saudi Med J 21: 200-201, 2000.

17. Jiao CL, Chen XY and Feng JX: Novel insights into the pathogenesis of Hirschsprung's-associated enterocolitis. Chin Med J (Engl) 129: 1491-1497, 2016.

18. Wang JH, Liu YZ, Yin LJ, Chen L, Huang J, Liu Y, Zhang RX, Zhou LY, Yang QJ, Luo JY, et al: BMP9 and COX-2 form an important regulatory loop in BMP9-induced osteogenic differentiation of mesenchymal stem cells. Bone 57: 311-321, 2013.

19. Chen K, Xie W, Luo B, Xiao W, Teitelbaum DH, Yang H, Zhang $\mathrm{K}$ and Zhang $\mathrm{C}$ : Intestinal mucosal barrier is injured by BMP2/4 via activation of NF- $\kappa$ B signals after ischemic reperfusion. Mediators Inflamm 901530: 2016, 2014.

20. Arnold SJ, Maretto S, Islam A, Bikoff EK and Robertson EJ: Dose-dependent Smad1, Smad5 and Smad8 signaling in the early mouse embryo. Dev Biol 296: 104-118, 2006.

21. Hegarty SV, O'Keeffe GW and Sullivan AM: BMP-Smad 1/5/8 signalling in the development of the nervous system. Prog Neurobiol 109: 28-41, 2013.

22. Aubin J, Davy A and Soriano P: In vivo convergence of BMP and MAPK signaling pathways: Impact of differential Smad1 phosphorylation on development and homeostasis. Genes Dev 18: 1482-1494, 2004

23. Blank U, Seto ML, Adams DC, Wojchowski DM, Karolak MJ and Oxburgh L: An in vivo reporter of BMP signaling in organogenesis reveals targets in the developing kidney. BMC Dev Biol 8: 86,2008 .

24. Henningfeld KA, Rastegar S, Adler G and Knöchel W: Smad1 and Smad4 are components of the bone morphogenetic protein-4 (BMP-4)-induced transcription complex of the Xvent-2B promoter. J Biol Chem 275: 21827-21835, 2000.

25. Chalazonitis A, Pham TD, Li Z, Roman D, Guha U, Gomes W, Kan L, Kessler JA and Gershon MD: Bone morphogenetic protein regulation of enteric neuronal phenotypic diversity: Relationship to timing of cell cycle exit. J Comp Neurol 509: 474-492, 2008.

This work is licensed under a Creative Commons Attribution-NonCommercial-NoDerivatives 4.0 International (CC BY-NC-ND 4.0) License. 